\title{
Radioimmunoassay typing gives a more precise definition of the HLA association of Type 1 (insulin-dependent) diabetes
}

\author{
R. Tosi ${ }^{1}$, M.Vela ${ }^{2}$, D. Adorno ${ }^{3}$, A. Longo ${ }^{4}$, F. Papola ${ }^{3}$, D. Maccarone ${ }^{3}$, D.Centis ${ }^{1}$, N. Tanigaki ${ }^{5}$, M. P. Raponi ${ }^{2}$, \\ A. Candela ${ }^{2}$, L. Campea ${ }^{2}$, M. Orsini ${ }^{2}$ and G. B. Ferrara ${ }^{4}$ \\ ${ }^{1}$ Laboratory of Cell Biology, CNR and ${ }^{2}$ Servizio di Diabetologia Pediatrica, Istituto di Clinica Pediatrica, Università "La Sapienza", Rome, \\ ${ }^{3}$ Istituto di Tipizzazione Tissutale, CNR, L'Aquila, and ${ }^{4}$ Istituto Tumori, Genova and AVIS, Bergamo, Italy; \\ ${ }^{5}$ Department of Molecular Immunology, Roswell Park Memorial Institute, Buffalo, NY, USA
}

\begin{abstract}
Summary. The problem of the HLA association of Type 1 (insulin-dependent) diabetes was re-examined by testing Class II antigenic specificities detectable by radioimmunoassay. Established (DRw53, DQw1, DQw2, DQw3) as well as newly described (DC5, DCalpha3) specificities were typed. The data obtained suggest that the association with DR3 and DR4 is
\end{abstract}

secondary to that with DQ specificities in linkage disequilibrium with DR3 and DR4.

Key words: RIA HLA typing, HLA association of Type 1 diabetes.
The association of Type 1 (insulin-dependent) diabetes with DR3 and DR4 has been firmly established [1-6]. However, a major unsolved problem is the precise identification, within the HLA-D region, of the gene or genes responsible for the development of the disease. In fact, the HLA-DR locus, to which the Type 1 diabetesassociated alleles DR3 and DR4 belong, is closely linked to at least three additional polymorphic loci. One resides in the same DR subregion and codes for the beta subunit of a second subset of DR molecules, also called BR subset [7]. Two are located in the DQ subregion and code for the alpha and beta subunit of DQ molecules. Between the alleles of these four polymorphic loci an extremely high degree of linkage disequilibrium exists so that they are arranged in relatively few haplotypic combinations which are transmitted "in block". Thus, the association with DR3 and DR4 merely indicates that there are factors contributing to susceptibility to Type 1 diabetes in the two haplotypes. However, the factors primarily involved could be either DR3 and DR4 themselves, or they could be other alleles at polymorphic loci in the DR/DQ subregions in linkage disequilibrium with DR3 and DR4. A more precise identification of the locus or loci involved may be proposed when additional polymorphic determinants in these subregions become recognizable, allowing a subdivision of DR3 and DR4 haplotypes in different subtypes. Depending on which subtypes turn out to be disease-associated, it should be possible to pinpoint the locus which is the most likely candidate for primary association.

By applying a radio-chemical analysis of Class II molecules, we have recently detected two additional DQ polymorphic determinants, DCalpha3 [8] and DC5
[9]. DCalpha3 is associated with DR3, 5 and w12 and DC5 is associated with DR4 and 5 and w12. Interestingly, DCalpha3 is possessed by all DR5 and DRw12 haplotypes but only by about $70 \%$ of DR3 haplotypes. Analogously, DC5 is present on all DR5 and DRw12 haplotypes but only on about $20 \%$ of the DR4 haplotypes. With the increased variety of available markers, it is now possible to distinguish two DR3 haplotypes (DCalpha3-positive and DCalpha3-negative) and two DR4 haplotypes (DC5-positive and DC5-negative). It is then important to test whether Type 1 diabetes is associated with DR3 and DR4 irrespective of the alternative markers present on the same haplotypes or, on the contrary, whether there is a selective association with some haplotypes and not with others.

The present report addresses this issue through the typing of 100 Type 1 diabetes probands by radioimmunoassay.

\section{Subjects and methods}

\section{Patients}

All patients included in this study had been followed by the Juvenile Diabetes Service of the Pediatrics Clinic of the University of Rome. They were diagnosed as having Type 1 diabetes according to the criteria of the National Diabetes Data Group [10] and were of Italian Caucasoid origin. The patients presented in this study were all unrelated. Of the 100 patients, there were 51 males and 49 females with mean age of diabetes 10.1, range 2-30years. All patients had been typed for HLA-A,B,C and DR specificities by the cytotoxicity test.

\section{Radioimmunoassay typing}

The radioimmunoassay typing consisted of immune-inhibition assays using lymphocyte lysates. Purified, radio-iodinated Class II molecules 
Table 1. RIA typing of Type 1 (insulin-dependent) diabetic patients

\begin{tabular}{|c|c|c|c|c|}
\hline $\begin{array}{l}\text { A. Experime } \\
\text { Specificity }\end{array}$ & $\begin{array}{l}1 \text { details of r } \\
\text { Locus }\end{array}$ & $\begin{array}{l}\text { immunoas } \\
\text { Labeled } \\
\text { antigen }\end{array}$ & Antiserum & $\begin{array}{l}\text { Refer- } \\
\text { ences }\end{array}$ \\
\hline DRw53 & DRbetaIII & $\begin{array}{l}\text { U698M } \\
(\mathrm{DR} 2,4)\end{array}$ & $\mathrm{HON}$ & 23 \\
\hline DQw1 & $\begin{array}{c}\text { DQ (alpha } \\
\text { or beta) }\end{array}$ & $\begin{array}{l}\text { Daudi } \\
\text { (DRw6) }\end{array}$ & $\mathrm{Fe} 131 / 4$ & 24 \\
\hline DQw2 & DQ(beta?) & $\begin{array}{l}\text { LG10 } \\
(\mathrm{DR} 7 / 7)\end{array}$ & $\mathrm{Fe} 96 / 19$ & 25 \\
\hline DQw3 & DQ(beta?) & $\begin{array}{l}\text { LG38 } \\
\text { (DR5/5) }\end{array}$ & 8 w108 & 26 \\
\hline DCalpha3 & DQ(alpha) & $\begin{array}{l}\text { LG38 } \\
\text { (DR5/5) }\end{array}$ & $\mathrm{T} 030 / 18$ & 8 \\
\hline DC5 & DQ(beta?) & $\begin{array}{l}\text { LG38 } \\
\text { (DR5/5) }\end{array}$ & $8 \mathrm{w} 1062$ & 9 \\
\hline
\end{tabular}

B. Typing results

Specificity Associated subtypic $+/++/-\quad-1+-/-$ specificities

\begin{tabular}{llllrl}
\hline DRw53 & DR4, w9 & 66 & 0 & 0 & 34 \\
DQw1 & DR1, 2, w6, w10 & 36 & 0 & 0 & 64 \\
DQw2 & DR(3), (7) & 67 & 0 & 2 & 31 \\
DQw3 & DR(4), 5, (7), w12 & 65 & 0 & 12 & 23 \\
DCalpha3 & DR(3), 5, w12 & 72 & 0 & 0 & 28 \\
DC5 & DR(4), 5, w12 & 16 & 0 & 49 & 35 \\
\hline
\end{tabular}

Table 2. Distribution of DQ specificities associated with DR3 and DR4 in Type 1 diabetic patients and in normal controls

\begin{tabular}{|c|c|c|c|}
\hline & \multicolumn{2}{|c|}{ Number of casses with phenotype } & \multirow[t]{2}{*}{ Total } \\
\hline & $\begin{array}{l}\text { DR3+ } \\
\text { DQw2 + } \\
\text { DCalpha3+ }\end{array}$ & $\begin{array}{l}\text { DR3 + } \\
\text { DQw2- } \\
\text { DCalpha3- }\end{array}$ & \\
\hline Patients & 61 & 0 & 61 \\
\hline Controls & 12 & 7 & 19 \\
\hline \multicolumn{4}{|c|}{$\mathrm{X}^{2}($ Yates corr. $)=20.231 p=1.6 \times 10^{-5}$} \\
\hline & $\begin{array}{l}\text { DR4+ } \\
\text { DC5 }+\end{array}$ & $\begin{array}{l}\text { DR4+ } \\
\text { DC5 - }\end{array}$ & \\
\hline Patients & 4 & 49 & 53 \\
\hline Controls & 7 & 14 & 21 \\
\hline \multicolumn{4}{|c|}{$\mathrm{X}^{2}$ (Yates corr. $)=5.996 p=0.008$} \\
\hline
\end{tabular}

carrying the alloantigenic determinant under test provided the labelled antigen. Their binding by the corresponding alloantiserum is competed by the lymphocyte sample if this contains the antigen being tested. The general methodology involved has been described previously $[11,12]$. The typing of each antigen required the establishment of a specific radioimmunoassay comprised of a suitable radio-labeled Class II preparation and its corresponding alloantiserum. For example, typing of DC5 was performed as follows: Class II molecules were purified starting from a DC5-positive lymphoblastoid cell line, LG38 (DR5; DRw52; DQw3; DC5; DCalpha3), and were labelled with ${ }^{125} \mathrm{I}$. DQ molecules, where the DC5 determinant is located, were then enriched by eliminating DR molecules with a rabbit anti-DR alpha antiserum. The labelled preparation thus obtained was matched with a specific anti-DC5 alloantiserum, T030/18. This binding was detected by a double precipitation test, using goat anti-rabbit immunoglobulin as the precipitating reagent. Finally, lysates from cells to be tested, obtained by adding to cell pellets a non-ionic detergent, Renex-30, were added to the reaction mixture and their effect on the binding was measured. Inhibition corresponded to DC5-positivity, and lack of inhibition to DC5-negativity. Detailed experimental conditions for each radioimmunoassay have been listed in Table 1 .

\section{Results}

A group of 100 unrelated Type 1 diabetic patients were studied. Cytotoxicity typing showed that 85 patients were positive for DR3 and/or DR4, with 28 DR3-positive, 24 DR4-positive and 33 DR3/4 heterozygotes. Lymphocyte samples from the patients were lysed by addition of a non-ionic detergent (see Methods) and tested as inhibitors of the binding reactions listed in Table 1A. All these specificities can be defined as "supertypic", since they are associated, due to linkage disequilibrium, with two or more DR specificities which are thus "subtypic" to them. Some of these associations are complete, while others are partial and are indicated in brackets in Table 1B. The association of DQw1 with DR1 is complete, since $100 \%$ of DR1-positive individuals are also DQw1-positive; the association of DQw2 with DR3 is partial, since only about $65 \%$ of DR3-positive normal individuals are also DQw2-positive. The data obtained in the patients with reference to the known association patterns are shown in Table 1B. Positivity for DRw53 and DQw1 followed the distribution of their associated subtypic specificities with no exceptions. DQw2 was positive in all 61 DR3-positive individuals (including four DR3/7 heterozygotes) and in 6 out of the 8 remaining DR7-positive individuals. Two of the DR7 patients possessed the less frequent DQw3-associated DR7 haplotype which is also associated with Dw11 (11). DQw3 was positive in all 12 DR5 patients (including four DR4/5 heterozygotes) in the two abovementioned DR7 patients and in 51 of the remaining 53 DR4 patients. Two of the DR4 patients typed negative for $D Q w 3$. This corresponds to a particular DR subtype associated with the Dw15 specificity and which is more usually found in Asian populations. Ten of the DR7 individuals (i. e. those DQw2-associated) were also negative for DQw3. DCalpha3 was positive in all DR3 and DR5 patients (including one DR3/5 heterozygote). DC5 was positive in all 12 DR5-positive patients (including four DR4/5 heterozygotes) and in four of the remaining DR4 patients.

The most relevant data concern the definition of the haplotypes involving DR3 and DR4. All 61 DR3-positive patients possessed the DR3-positive, DQw2-positive, DCalpha3-positive haplotype. This is significantly different from the distribution in the normal population, $\left(p=1.6 \times 10^{-5}\right)$, where 7 individuals out of 19 tested carried the alternative DR3-positive, DQw2-negative, DCalpha3-negative haplotype (Table 2). A similar, though less significant deviation was observed for DR4 in its association with the new DQ specificity DC5. Among DR4-positive patients, only those negative for DR5 were considered for this calculation, since the DC5-positivity would be contributed by the DR5 haplotype. Out of the 53 DR4-positive patients, only four were DC5-positive. This is significantly different from normal population $(\mathrm{p}=0.008)$, where 7 individuals out of 21 tested were DC5-positive (Table 2). Two DC5-pos- 
itive patients were found in the DR4/X group, and an other two in the DR3/4 group.

\section{Discussion}

Previous studies performed at the DNA level have suggested that Type 1 diabetes may have a stronger association with restriction fragment polymorphisms in the DQ rather than in the DR region $[12,13,14]$. Obviously this does not constitute a proof of an higher association with polymorphic variations of the products of the HLA DQ region. This possibility must be tested necessarily at the protein (or at the RNA) level. Typing of DQ specificities by the classical cytotoxicity test presents some problems due to the low representation of DQ molecules on the cell surface as compared with DR molecules and to the presence in DQ antisera of antibodies against "subtypic" DR specificities associated, by linkage disequilibrium, with the DQ specificity under test. These problems are avoided by using immunochemical methods, where purified DQ molecules can be used as labelled antigens. RIA typing offers additional advantages in terms of specificity and reproducibility as previously discussed $[11,15]$. The availability of purified, radio-labeled Class II antigens makes it possible to set up binding reactions with specific alloantisera, revealing distinct antigenic determinants. Lymphoid cells can compete for the binding of the radio-labelled antigen if they possess the same determinant. Accordingly, lymphocyte samples can be typed as positive or negative based on their inhibition capacity. This method provides a reliable typing of known supertypic specificities such as "second DR" or "BR" locus determinants (DRw52 and DRw53) and DQ determinants (DQw1,-w2 and -w3). In addition, some newly discovered DQ specificities, such as DC5 and DCalpha3, which are relevant to the HLA association of Type 1 diabetes (see above), can only currently be typed by radioimmunoassay.

The data obtained show that Type 1 diabetes is associated with only one of the two recognizable DR3 haplotypes, i.e. with the DR3; DRw52; DCalpha3; DQw2 haplotype and not with the DR3; DRw52; blank; blank haplotype. The $61 \mathrm{DR} 3$-positive patients, with no exception, possessed the former haplotype. The logical conclusion is that the "true" association of the disease is not with DR3 but, possibly, with a DQ determinant. The DQ determinants directly involved in the disease, however, cannot be DCalpha3 or DQw2 themselves, because these specificities are not exclusive to the DR3 haplotype. Both in patients and in controls DCalpha3 is supertypic to DR3 and DR5, and DQw2 is supertypic to DR3 and DR7. Neither DR5 or DR7 are associated with Type 1 diabetes. Thus, the structure directly associated with the disease must be either another polymorphic variation in linkage disequilibrium with DCalpha3 and DQw2 or some "new" determinant generated by specific DQalpha-DQbeta subunit associations (see below).
As to DR4, Type 1 diabetes appears to be associated with the DR4; DRw53; DQw3; DC5-negative haplotype rather than the DR4; DRw53; DQw3; DC5-positive haplotype. This differential association is significant. It is, however, not so evident as in the case of DR3, since four exceptions were observed out of 57 DR4-positive patients. Thus, in the case of DR4 it also seems more likely that the association is with a DQ determinant rather than with DR4, which is shared by both associated and non-associated haplotypes.

These conclusions, based on serological analysis, can be questioned if one bears in mind that different structures may underlie the same serological specificity. Thus, the diabetes-associated and the non-diabetes-associated DR3 or DR4, although indistinguishable by serology because of the limited discrimination power of alloantisera, may nevertheless be different structurally. This structural difference, in a DR gene, could be responsible for susceptibility to diabetes. Such a possibility is difficult to eliminate. Indeed, very limited sequence differences have been demonstrated in DR4 genes of different haplotypes [16]. Similar information is not yet available for the DR3 subtypes. Therefore, conclusions based simply on serology must be taken with caution until the precise structural basis of each specificity is known. Parallel evidence for a DQ rather than DR association of Type 1 diabetes comes from restriction fragment length polymorphism studies showing a high degree of association with patterns detected by a beta-DQ probe $[12,13]$ and by an alpha-DQ probe [14]. Some of the data obtained with a beta-DQ probe can be directly related to our observation. As shown by Cohen-Haguenauer et al. [13] DR4-positive individuals may possess one of two fragment clusters, DQR4 and DQR5, the latter being shared by DR5-positive individuals. Type 1 diabetic patients show a predominance of the DQR4 cluster. An obvious parallelism can be seen between DQR5 and DC5 as to their distribution in the normal population as well as in Type 1 diabetic patients.

A DQ association of the disease would help us understand the deviation from Hardy-Weinberg equilibrium consistently detected in all studies. According to an appealing hypothesis [17], the susceptibility to diabetes would be due to an heterozygous determinant originating from the association of DQ alpha subunit of one haplotype and the DQ beta subunit of the other involved haplotype. Since, unlike the case of DR genes, both DQ genes are polymorphic, conceivably only some alpha-beta associations and not others are effective. This would explain the high proportion of DR3/4 heterozygotes $[3,4,18-20]$, the higher degree of concordance of DR3/4 monozygotic twins [21] and the decreased proportion of either DR3/3 or $4 / 4$ homozygotes which has also been observed in some studies [3, 19]. Also, it would explain why, unlike most HLA Class II-associated diseases, Type 1 diabetes is associated not with a single haplotype with two haplotypes which do not share any recognizable specificity. In a 
similar case, i. e. coeliac disease, the apparent association with two DR alleles, DR3 and DR7, could be explained by their sharing a defined DQ specificity, i.e. DQw2 [22]. This is clearly not the case for Type 1 diabetes, for which a different explanation must be sought.

Our data demonstrate that patients which are DR3/4 heterozygous almost always (in 31 cases out of 33) possess both "pathological" haplotypes, i.e. DR3; DRw52; DCalpha3; DQw2 and DR4; DRw53; DQw3, DC5-negative. This cannot be easily explained if the development of the disease originates from a single gene product. It is better understood if a sort of "cooperation" is required between the products of the two haplotypes, perhaps as complementation of DQ genes.

Acknowledgements. This investigation was supported by the Progetto Finalizzato Ingegneria Genetica-Basi Molecolari delle malattie ereditarie of the Consiglio Nazionale delle Ricerche, by the NATO grant 82/0491 and by the United States Public Health Grant AI-20251.

\section{References}

1. Batchelor JR, Morris PJ (1977) Joint report on HLA and disease: juvenile-onset diabetes. In: Bodmer WF, Batchelor JR, Bodmer JC, Festenstein H, Morris PJ (eds) Histocompatibility testing. Munksgaard Copenhagen, pp 211-213

2. Nerup J, Christy M, Platz P, Ryder P, Svejgaard A (1984) Aspects of the genetics of insulin-dependent diabetes mellitus. In: Andreani D, Di Mario U, Federlin KF, Heding LG (eds) Immunology in diabetes. Kimpton, London, pp 63-69

3. De Jongh BM, Bruining GJ, Schreuder GM, Schuurman RKB, Radder JK, Van Loghem E, Meera Khan P, Hauptmann G, Van Rood JJ (1984) HLA and GM in insulin-dependent diabetes in the Netherlands: report on a combined multiplex family and population study. Human Immunol 10: 5-21

4. Wolf E, Spencer KM, Cudworth AG (1983) The genetic susceptibility to Type I (insulin-dependent) diabetes: analysis of the HLADR association. Diabetologia 24: 224-230

5. Serrano-Rios M, Regueiro JR, Severino R, Lopez-Larrea C, Arnaiz-Villena A (1983) HLA antigens in insulin dependent and noninsulin dependent spanish diabetic patients. Diabete Metab 9: $116-120$

6. Dundon S, Finch A (1983) Type 1 (insulin dependent) diabetes mellitus in children - HLA DR antigen association. Irish Med $\mathbf{J}$ $76: 255-258$

7. Tanigaki N, Tosi R (1982) The genetic control of human I a alloantigens: a three loci model derived from the immunochemical analysis of supertypic specificities. Immunological Rev 66:5-37

8. Tosi R, Tanigaki N, Sorrentino R, Centis D, Ferrara GB (1984) Serologically detectable polymorphism of the HLA-DC alpha subunit. J Immunol 132: 277-282

9. Tanigaki N, Tosi R, Centis D, Ferrara GB (1985) DR5-associated DC molecules carry three different allospecificities. Human Immunol 12: 47-57

10. Diabetes Data Group (1979) Classification and diagnosis of diabetes mellitus and other cathegories of glucose intolerance. Diabetes 28: 1039-1057

11. Tosi R, Tanigaki N, Centis D, Rossi PL, Alfano G, Ferrara GB, Pressman D (1980) HLA DR typing by radio-immunoassay. Transplantation 29:302-305
12. Owerbach D, Lernmark A, Platz P, Ryder LP, Rask L, Peterson PA, Ludvigsson J (1983) HLA-D region beta chain DNA endonuclease fragments differ between HLA-DR identical healthy and insulin-dependent diabetic individuals. Nature 303: 815-817

13. Cohen-Haguenauer O, Robbins E, Massart C, Busson M, Deschamps I, Hors J, Lalouel JM, Dausset J, Cohen D (1985) A systematic study of HLA Class II-beta DNA restriction fragments in insulin-dependent diabetes mellitus. Proc Natl Acad Sci 82: 3335-3339

14. Hitman GA, Sachs J, Cassell P, Awad J, Bottazzo GF, Tarn AC, Schwartz AC, Monson JP, Festenstein H (1986) A DR3-related DX alpha gene polymorphism strongly associates with insulin-dependent diabetes mellitus

15. Tanigaki N, Tosi R (1982) Assessment of the specificity of human alloantisera and alloantigens by the use of radioiodinated human I a antigens. Tissue Antigens 20:1-21

16. Cairns JS, Curtsinger JM, Dahl CA, Freeman S, Alter BJ, Bach FH (1985) Sequence polymorphism of HLA DRbetal alleles relating to T-cell-recognized determinants. Nature 317: 166-168

17. Bodmer WF (1984) The HLA system, 1984. In: Albert E, Baur MP, Mayr WR (eds) Histocompatibility Testing 1984, Springer, Berlin Heidelberg New York Tokyo, pp 11-22

18. Amoroso A, Borelli I, De Marchi M, Savi M, Pagano G, Cavalot F, Curtoni ES (1983) HLA e diabete di tipo 1: studio prospettico di tutti i nuovi casi diagnosticati in Piemonte in un anno. Pathologica 75 (Suppl): $40-50$

19. Contu L, Deschamps I, Lestradet H, Hors J, Schmid M, Busson M, Benajam A, Marcelli-Barge A, Dausset J (1982) HLA haplotype study of 53 juvenile insulin-dependent (I.D.D) families. Tissue Antigens 20: $123-140$

20. Winearls BC, Bodmer JG, Bodmer WF, Bottazzo GF, MaNally J, Mann JI, Thorogood M, Smith MA, Baum JD (1984) A family study of the association between insulin-dependent diabetes melitus, autoantibodies and the HLA system. Tissue Antigens 24: $234-246$.

21. Johnston C, Pyke DA, Cudworth AG, Wolf E (1983) HLA-DR typing in identical twins with insulin-dependent diabetes: difference between concordant and discordant pairs. Br Med J 286: $253-255$

22. Tosi R, Vismara D, Tanigaki N, Ferrara GB, Ciccimarra F, Buffolano W, Follo D, Auricchio S (1983) Evidence that coeliac disease is primarily associated with a DC locus allelic specificity. Clin Immunol Immunopathol 28: 395-404

23. Katagiri M, Ikeda H, Maruyama N, Moriuchi J, Wakiska A, Kimura S, Aizawa M, Itakura K (1979) Evidence for two B-cell alloantigen loci in the HLA-D region. Immunogenetics 9: 335-341

24. Tosi R, Tanigaki N, Centis D, Ferrara GB, Pressman D (1978) Serological dissection of human Ia molecules. J Exp Med 148: $1592-1611$

25. Tanigaki N, Tosi R, Duquesnoy R, Ferrara GB (1982) Three Ia species with different structures and alloantigenic determinants in an HLA-homozygous cell line. J Exp Med 157: 231-247

26. Tanigaki N, Tosi R, Sagawa K, Minowada J, Ferrara GB (1983) The distribution of DR5, MT2 and MB3 specificities on human Ia subsets. Immunogenetics 17: 371-386

Received: 30 January 1986

and in revised form: 5 May 1986

Dr. Roberto Tosi

Istituto di Biologia Cellulare

Via Romagnosi 18 a

I-00196 Rome

Italy 